\title{
PTK (protein tyrosine kinase)-6 and HER2 and 4, but not HERI and 3 predict long-term survival in breast carcinomas
}

\author{
M Aubele*,1,2, G Auer ${ }^{3}$, AK Walch ${ }^{1,4}$, A Munro5, MJ Atkinson ${ }^{1,2}$, H Braselmann ${ }^{6}$, T Fornander ${ }^{3}$ \\ and JMS Bartlett ${ }^{5}$
}

'GSF-National Research Center for Environment and Health, Institute of Pathology, D-85764 Neuherberg, Germany; ${ }^{2}$ Technical University of Munich, Institute of Pathology, Trogerstr. 18, 81675 München, Germany; ${ }^{3}$ Department of Oncology and Pathology, Karolinska Institute and Hospital, S- 7 I 76 , Stockholm, Sweden; ${ }^{4}$ Institute of Pathology, Universitätsklinikum Freiburg, Breisacher Straßel I 5a, 79106 Freiburg I., Br., Germany; ${ }^{5}$ Endocrine Cancer Group, Cancer Research Centre, Western General Hospital, Crewe Road, EH4 2XR, South Edinburgh, UK; ${ }^{6}$ GSF-National Research Center for Environment and Health, Institute of Molecular Radiation Biology, D-85764, Neuherberg, Germany

The HER receptors are of therapeutic and prognostic significance in breast cancer, and their function is modulated by cytoplasmic tyrosine kinases like PTK6 (brk). We performed a retrospective study on archival breast cancer samples from patients with long follow-up and compared the protein expression between individual HERs and between HERs and the PTK6. Univariate and multivariate analyses were used to study the prognostic value of parameters. Metastases-free survival of patients for longer than 240 months was inversely associated $(P \leqslant 0.05)$ with nodal status, tumour size, and oestrogen receptor status, but was also directly associated with high protein expression levels of HER4 and PTK6 in Kaplan-Meier analysis. In multivariate analysis for metastases-free survival of $>240$ months, the stepwise selected parameters were tumour size (relative risk 3. I), PTK6 expression (0.4), and number of positive lymph nodes (I.2). Furthermore, we demonstrated a timedependence of the prognostic value attributed to the parameters. The HER receptors (HER2,4), but not PTK6, were independent prognostic markers for metastases-free survival at 60 months, whereas at 240 months PTK6 is the strongest prognostic marker. We demonstrate that PTK6 is a prognostic marker of metastases-free survival in breast cancer, and is independent of the classical morphological and molecular markers of lymph node involvement, tumour size, and HER2 status.

British Journal of Cancer (2007) 96, 80 I-807. doi: I0.1038/sj.bjc.66036I3 www.bjcancer.com

Published online I 3 February 2007

(c) 2007 Cancer Research UK

Keywords: PTK6 (BRK) expression; HER receptors; breast cancer; prognosis

The cytoplasmic non-receptor tyrosine kinase (BRK, PTK6), originally cloned from a human metastatic breast tumour (Mitchell et al, 1994), shows elevated expression in breast carcinoma cell lines and in approximately two-thirds of primary breast tumours (Mitchell et al, 1994; Barker et al, 1997; Llor et al, 1999; Born et al, 2005). Overexpression of PTK6-mRNA positively correlates with hormone receptor status (Zhao et al, 2003) and HER2/NEU expression (Born et al, 2005) in breast cancer specimens. Several in vitro studies of PTK6 point to a possible role in modulating signal transduction of receptor tyrosine kinases (RTKs): PTK6 expression increases HER3 phosphorylation and Akt activation (Kamalati et al, 2000; Zhang et al, 2005), sensitises cells to epidermal growth factor (EGF) (Kamalati et al, 1996), which activates PTK6 (Kamalati et al, 2000; Chen et al, 2004), and influences the apoptotic pathway (Haegebarth et al, 2005). There are, however, several unanswered questions with regard to the structure, activity, and regulation of PTK6. It was shown by Haegebarth et al (2005) that PTK6 negatively regulates the activity of RNA-binding

\footnotetext{
*Correspondence: Dr M Aubele, GSF-Forschungszentrum für Umwelt und Gesundheit, Institut für Pathologie, Ingolstädter Landstrasse I, 85764 Neuherberg, Germany; E-mail: aubele@gsf.de

Received 30 October 2006; revised 3 January 2007; accepted 9 January 2007; published online 13 February 2007
}

proteins, which may have an impact on the post-transcriptional regulation of gene expression (Haegebarth et al, 2005). Furthermore, PTK6 possesses sequences that predicted to form Src homology (SH3 and SH2) domains (Kamalati et al, 1996; Zhang et al, 2005), suggesting interactions with other proteins. Because of the known involvement of Src in epithelial tumour development and structural similarities with Src, it is thought that PTK6 may play a role in epithelial tumorigenesis (Petro et al, 2004; Zhang et al, 2005).

The EGF receptor family is composed of four members: EGFR/ HER1/erbB1, HER2/NEU/erbB2, HER3/erbB3, and HER4/erbB4 (Mendelsohn et al, 2000; Hudelist et al, 2003; Lodge et al, 2003; Abd El-Rehim et al, 2004; Hynes et al, 2005). There is a growing body of evidence that members of the HER family are involved in breast cancer development and progression, but the protein expression pattern of all four HER receptors remains poorly understood (Bieche et al, 2003; Witton et al, 2003; Abd El-Rehim et al, 2004; Tovey et al, 2005; Bianchi et al, 2006). HER1 and HER2 have been consistently associated with a poor prognosis (Witton et al, 2003; Abd El-Rehim et al, 2004; Wiseman et al, 2005), whereas conflicting evidence is available on the prognostic significance of HER3 (Kew et al, 2000; Bieche et al, 2003; Tovey et al, 2004), and HER4 has been more consistently linked to good prognostic factors (PFs) (Witton et al, 2003; Abd El-Rehim et al, 2004; Tovey et al, 2004). 
The EGFR-family molecules are outstanding candidate targets for tumour therapy. In breast carcinomas it has been shown that HER2/NEU amplification/overexpression has therapeutic and prognostic implications (Slamon 1990; Meric et al, 2002; Hudelist et al, 2003; Witton et al, 2003; Abd El-Rehim et al, 2004; Bianchi et al, 2006), and that the monoclonal antibody trastuzumab directed against HER2/NEU is therapeutically active in HER2positive breast carcinomas (Meric et al, 2002; Menard et al, 2003). However, a number of HER2/NEU-positive tumours are not responsive to HER2/NEU-directed therapy (Menard et al, 2003; Hynes et al, 2005), indicating that other HER receptors as well as additional signalling molecules may influence the biological response to trastuzumab.

Ligand binding by HER/erbB receptors induces the formation of receptor homo- or heterodimers and activation of the intrinsic receptor kinase domain, resulting in phosphorylation on specific tyrosine residues (Olayioye et al, 2000; Hynes et al, 2005) and the creation of binding sites for proteins containing Src homology (SH2-/SH3-) domains (Hudelist et al, 2003). The composition of these receptor dimers is thought to influence both quality and quantity of downstream signalling pathways and to determine the cellular response (Olayioye et al, 2000; Hudelist et al, 2003; Hynes et al, 2005). Further, cytoplasmic protein tyrosine kinases containing $\mathrm{SH} 2$ or $\mathrm{SH} 3$ domains may also modify the RTK signalling (Petro et al, 2004; Zhang et al, 2005). One such nonreceptor protein tyrosine kinase, PTK6 (BRK), is similar to the Src family kinase and includes structural motifs comprising $\mathrm{SH} 2$ and $\mathrm{SH} 3$ domains.

No study has so far tested the hypothesis that PTK6 may have an impact upon breast cancer prognosis or tested its association with the HER family of RTKs in breast carcinoma tissue. Because of the correlation between PTK6 and HER expression, it is possible that these proteins are together of diagnostic/prognostic relevance. We investigated the protein expression of the HER1-HER4 receptors and of the PTK6 in invasive breast carcinomas with long-term follow-up, and found a previously undescribed time-dependent prognostic relevance of PTK6 using multivariate analysis.

\section{MATERIALS AND METHODS}

\section{Patients and tumour samples}

All studies were performed using formalin-fixed, paraffinembedded, archival material from invasive breast carcinomas obtained from 193 patients. The patients age ranged from 27 to 84 years (median 66 years), 52 patients were premenopausal, 141 were postmenopausal. The hormone receptor status was evaluated immunohistochemically, revealing that 92 of the tumours were hormone receptor positive. Histological classification (WHO, 2003) defined 168 tumours as being invasive ductal, not otherwise specified. The remaining 25 cases were classified as tubular (7), lobular (9), papillary (3), and medullary (6). A total of 126 cases were classified as grade 2,48 cases as grade 3 , and 19 cases as grade 1, according to Elston and Ellis (1991). Ninety-nine of the tumours were lymph-node-negative, 94 were node-positive, and the majority of the tumours in this study were less than $2 \mathrm{~cm}$ in size $(n=135)$.

Detailed long-term clinical follow-up was available for 105 patients. These patients do not significantly differ from the full cohort of 193 patients in their clinicohistological parameters. These patients were all surgically treated, and no patient received preoperative treatment. Fifty-four patients did not receive postoperative treatment, whereas adjuvant radio- or chemotherapy was administered to 47 of the patients, and 14 patients received antihormonal treatment. The median clinical follow-up of patients was 144 months (mean 140, range 5-264 months) with 37 patients relapsing with distant metastases and 15 with local recurrence.
Ethical approval for the study was obtained from the Ethics Committee of the medical faculty of the Technical University of Munich.

\section{Tissue microarrays}

Tissue Microarray (TMA) construction was performed as described (Richter et al, 2000). A haematoxylin- and eosin-stained section from each paraffin block was used to define representative tumour regions. Tissue cylinders of $0.6 \mathrm{~mm}^{2}$ in diameter were punched from each paraffin block and transferred to the recipient paraffin block using a tissue-arraying instrument (Beecher Instruments Inc., Silver Spring, MD, USA). From the resulting TMA blocks, $5-\mu \mathrm{m}$ sections were cut and transferred to adhesive slides using the 'paraffin-tape-transfer-system' (Instrumedics, Hackensack, NJ, USA). Both the TMA and punched block were re-examined to validate representative sampling.

\section{Immunohistochemistry}

For immunohistochemistry (IHC), which was performed on all 193 tumours, the following antibodies were used on the TMA sections: HER1 (erbB1/EGFR; 31G7, Invitrogen, Heidelberg, Germany, dilution 1:50); HER2 (erbB2; Hercept kit, K5204, DAKO GmbH, Hamburg, Germany); HER3 (erbB3; H3.105. 5, Stratech, Suffolk, England, 1:20); HER4 (erbB4; H4.77.16, Stratech, 1:20); PTK6 (BRK, C-17, Santa Cruz Biotechnology, Heidelberg, Germany, $1: 100)$.

Deparaffinisation of the TMA sections, antigen retrieval, and incubation of the primary antibody was performed in general as described (Quintanilla-Martinez et al, 2003). For PTK6 IHC, the deparaffinised slides were microwave-cooked in $0.01 \mathrm{M}$ citrate buffer ( $\mathrm{pH} 6.0$ ) containing $0.1 \%$ Tween 20 at maximum power $(800 \mathrm{~W})$ for $8 \mathrm{~min}$. Thereafter, sections were washed in Trisbuffered saline ( $\mathrm{pH} 7.6)$ containing $5 \%$ fetal calf serum (Life Technologies, Grand Island, NY, USA) for $30 \mathrm{~min}$, and the PTK6 antibody was incubated overnight at room temperature. Staining and counterstaining were by an automated immunostainer (Ventana Medical System, Tucson, AZ, USA) (Quintanilla-Martinez et al, 2003).

Tissue staining intensities were scored blind for PTK6, HER3 and HER4 expression by two independent observers using a 4point scale, where $0=$ no staining, $1=$ light staining, $2=$ moderate staining, and $3=$ strong staining as published previously (Witton et al, 2003). HER1 and HER2 expression were scored using widely accepted criteria that assess the intensity and completeness of membrane staining (Jacobs et al, 1999; Ellis et al, 2001). Representative examples of the PTK6 expression classification as well as expression in normal ducts are given in Figure 1.

\section{Statistics}

Correlations among the markers, and between markers and clinical parameters, were examined by Spearman's rank correlation test. Survival analysis (for statistical details, see Allison, 1995) was performed using distant recurrence-free survival for follow-up periods of 60,120 , and 240 months, and for disease-free interval of 240 months. The distant recurrence-free survival represents the interval from surgery to the presentation of distant metastases. The disease-free interval was defined as the interval from the date of surgery to the first locoregional recurrence and/or distant metastases.

For univariate survival analysis Kaplan-Meier curves were calculated and differences between strata were tested with the $\log$-rank $\chi^{2}$ value. Multivariate analysis was performed using Cox proportional hazards regression, using a combined stepwise selection algorithm (SAS Institute, Cary, NC, USA). All parameters reaching a significance level of $P \leqslant 0.2$ in Kaplan-Meier analysis 


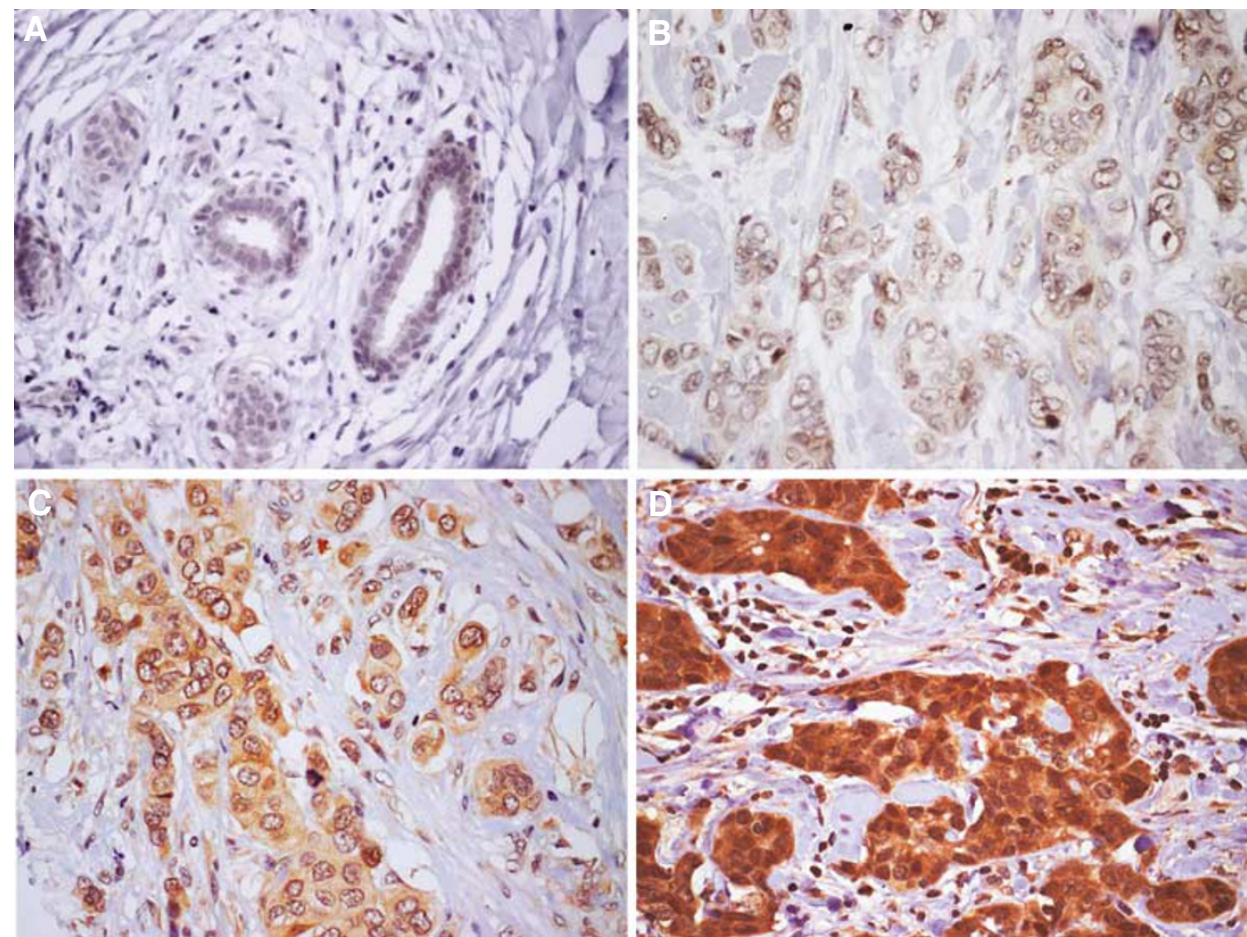

Figure I Representative examples of PTK6 IHC (objective magnification $\times 40$ ) in normal breast epithelium $(\mathbf{A})$, and in breast carcinomas classified as $1+(\mathbf{B}), 2+(\mathbf{C})$, and $3+(\mathbf{D})$.

Table I Frequencies of cases (number/percent of cases) scored as $0 / 1+/ 2+/ 3+$ according to their expression of HER receptors and PTK6 in primary breast carcinomas

\begin{tabular}{llllll}
\hline & HERI/EGFR & HER2/neu & HER3 & HER4 & PTK6 \\
\hline 0 & $146 / 81.1$ & $55 / 31.6$ & $1 / 0.6$ & $11 / 6.4$ & $72 / 42.1$ \\
$1+$ & $25 / 13.9$ & $74 / \mathbf{4 2 . 5}$ & $43 / 25.1$ & 73.8 \\
$2+$ & $4 / 2.2$ & $16 / 9.2$ & $99 / \mathbf{5 7 . 9}$ & $67 / 37.0$ \\
$3+$ & $5 / 2.8$ & $29 / 16.7$ & $28 / 16.4$ & $11 / 6.4$ & $75 / \mathbf{4 1 . 9}$ \\
\hline
\end{tabular}

The highest frequency for each marker is printed bold.

were offered to multivariate analysis. In all other tests, statistical significance was considered at the $P \leqslant 0.05$ level.

For illustration of the multivariate result the parameters, weighted by their coefficients, were used to calculate a new prognostic variable PF (Aubele et al, 1995), and patients were grouped according to their PF for Kaplan-Meier analysis.

\section{RESULTS}

\section{Associations between PTK6 and the HER receptors}

Using IHC, strong positivity $(2+, 3+)$ for the HER1 receptor was found in only $5 \%$ of the tumours, for HER2 in $26 \%$, for HER 3 in $74 \%$, for HER4 in 51\%, and for PTK6 in 59\% (Table 1). As shown in Table 2, significant correlations were identified among the HER receptors, and between individual HER receptors and PTK6. The strongest correlations $(P \leqslant 0.0001)$ were found between HER1 and HER3, between HER2 and PTK6, and between HER4 and PTK6. The histological grade of tumours was significantly associated with HER1, HER4, and with PTK6, and an inverse correlation was identified between the oestrogen receptor (ER) and HER 1 $(\leqslant 0.04)$. No significant association was present between the nodal
Table 2 Protein expression of HER receptors and PTK6 in invasive breast carcinomas

\begin{tabular}{|c|c|c|c|c|c|}
\hline & HER I & HER2 & HER3 & HER4 & PTK6 \\
\hline HERI & & n.s. & $\begin{array}{c}0.30 \\
<0.0001\end{array}$ & n.s. & n.s. \\
\hline HER2 & & & n.s. & $\begin{array}{l}0.16 \\
0.044\end{array}$ & $\begin{array}{c}0.31 \\
<0.0001\end{array}$ \\
\hline HER3 & & & & $\begin{array}{l}0.22 \\
0.004\end{array}$ & $\begin{array}{l}0.16 \\
0.047\end{array}$ \\
\hline HER4 & & & & & $\begin{array}{c}0.35 \\
<0.0001\end{array}$ \\
\hline Grade & $\begin{array}{l}0.22 \\
0.004\end{array}$ & n.s. & n.s. & $\begin{array}{l}0.21 \\
0.005\end{array}$ & $\begin{array}{l}0.18 \\
0.019\end{array}$ \\
\hline Nodal status & n.s. & n.s. & n.s. & n.s. & n.s. \\
\hline Tumour size & n.s. & n.s. & n.s. & n.s. & n.s. \\
\hline ER & $\begin{array}{l}-0.18 \\
0.023\end{array}$ & n.s. & n.s. & n.s. & n.s. \\
\hline $\operatorname{PrR}$ & n.s. & n.s. & n.s. & n.s. & n.s. \\
\hline
\end{tabular}

Correlations among and between HER receptors and PTK6 are given, as well as relation of markers to clinicopathological parameters (Spearman correlation coefficients, $P$-values, n.s. $=$ not significant, $E R=$ oestrogen and $\operatorname{PrR}=$ progesteron receptor status). 
status or the tumour size and all the immunohistochemical parameters.

To estimate the frequency of HER receptor dimer formation, we calculated the occurrence of combined overexpression of the markers, considering those showing immunohistochemical positivity above the median level as highly overexpressed, whereas a level below the median was considered as low expression (Table 3 ). High-level co-overexpression of the HER family members and the PTK6 occurred most frequently between HER3 and HER4 (37\% of the cases), between HER3 and PTK6 (40\% of cases), and between HER4 and PTK6 (34\% of the cases), whereas all other combinations were below $18 \%$ (Table 3 ).

\section{Prognostic relevance of PTK6 and the HER family members}

Univariate analysis In univariate analyses lymph node status $(P=0.001)$, tumour size $(P=0.002)$, and $\mathrm{ER}$ status were all inversely correlated with an event-free (distant recurrence) survival of patients longer than 240 months, whereas histological grade and type and the progesterone receptor status were not significant (Table 4).

A significant positive correlation with the event-free (distant recurrence) survival of patients was identified for HER4 $(P=0.015)$ and for PTK6 $(P=0.001)$. Figure 2 shows KaplanMeier curves demonstrating distant recurrence-free survival of patients with high $(2+/ 3+)$ vs low $(0 / 1+)$ levels of PTK6 and HER4 expression, respectively.

Multivariate prognostic analysis Multivariate analysis was used to assess the influence of markers on the distant recurrence-free survival of patients, together with that of the clinicopathological parameters. The stepwise selected parameters for a distant recurrence-free survival of patients were tumour size (relative risk

Table 3 High-level co-overexpression of HER receptors and PTK6 (number/percent of cases)

\begin{tabular}{lllll}
\hline & HER2 $\geqslant \mathbf{2}$ & HER3 $\geqslant \mathbf{2}$ & HER4 $\geqslant \mathbf{2}$ & PTK6 $\geqslant \mathbf{2}$ \\
\hline HER $I>0$ & $9 / 4.7$ & $29 / 15.0$ & $20 / 10.4$ & $22 / 11.4$ \\
HER2 $\geqslant 2$ & & $33 / 17.1$ & $27 / 14.0$ & $34 / 17.6$ \\
HER3 $\geqslant 2$ & & & $71 / \mathbf{3 6 . 8}$ & $77 / \mathbf{3 9 . 9}$ \\
HER4 $\geqslant 2$ & & & & $66 / 34.2$ \\
\hline
\end{tabular}

Low or high expression was defined being below or above the median level of the single parameters. The highest frequencies of marker combinations are printed bold.

Table 4 Results of Kaplan-Meier analysis of the single parameters for an event-free (distant recurrence) survival of patients of $>240$ months $(P$ values are given)

\begin{tabular}{lc}
\hline Parameter & P-value \\
\hline HERI & 0.66 \\
HER2 & 0.14 \\
HER3 & 0.19 \\
HER4 & $0.015^{\mathrm{a}}$ \\
PTK6 & $0.001^{\mathrm{a}}$ \\
PrR & 0.72 \\
ER & 0.007 \\
Lymph node status $+/-$ & 0.001 \\
Tumour size $(<20 />=20 \mathrm{~mm})$ & 0.002 \\
Histological grade & 0.26 \\
Histological type & 0.10 \\
\hline
\end{tabular}

Abbreviations: $E R=$ oestrogen and $\operatorname{PrR}=$ progesteron receptor status. ${ }^{\text {aHigh }}$ expression corresponds to better prognosis.
3.1), number of positive lymph nodes (1.2), and PTK6 expression (0.4). The $P$-values, coefficients, relative risk as well as the $95 \%$ confidence intervals are summarised in Table 5A.

To study the time dependence of the prognostic value of parameters, we performed multivariate analyses also for 60 months and for 120 months event-free (distant recurrence) survival. The results, which are summarised in Table $5 \mathrm{~B}$ and $\mathrm{C}$, show a strong time dependence of the prognostic meaning of single parameters. For an interval of 60 months tumour size (relative risk 4.2), HER2 expression (1.7), and the HER4 expression (0.4) were each independently prognostic. At a follow-up of 120 months, the protein expression of HER4 was no longer significant, instead PTK6 expression becomes meaningful. Here, the stepwise selected parameters were tumour size (relative risk 3.4), HER2 (1.5), and PTK6 (0.4). Summarizing these results, the protein expression of HER receptors (HER2, HER4) are of strong prognostic value in short-term survival analysis (60 and 120 months), whereas for a long interval of 240 months the prognostic value of the PTK6 is the strongest parameter in addition to tumour size and lymph node status.

Selecting patients' disease-free survival as the end point of the analysis resulted in similar selected parameters with the same
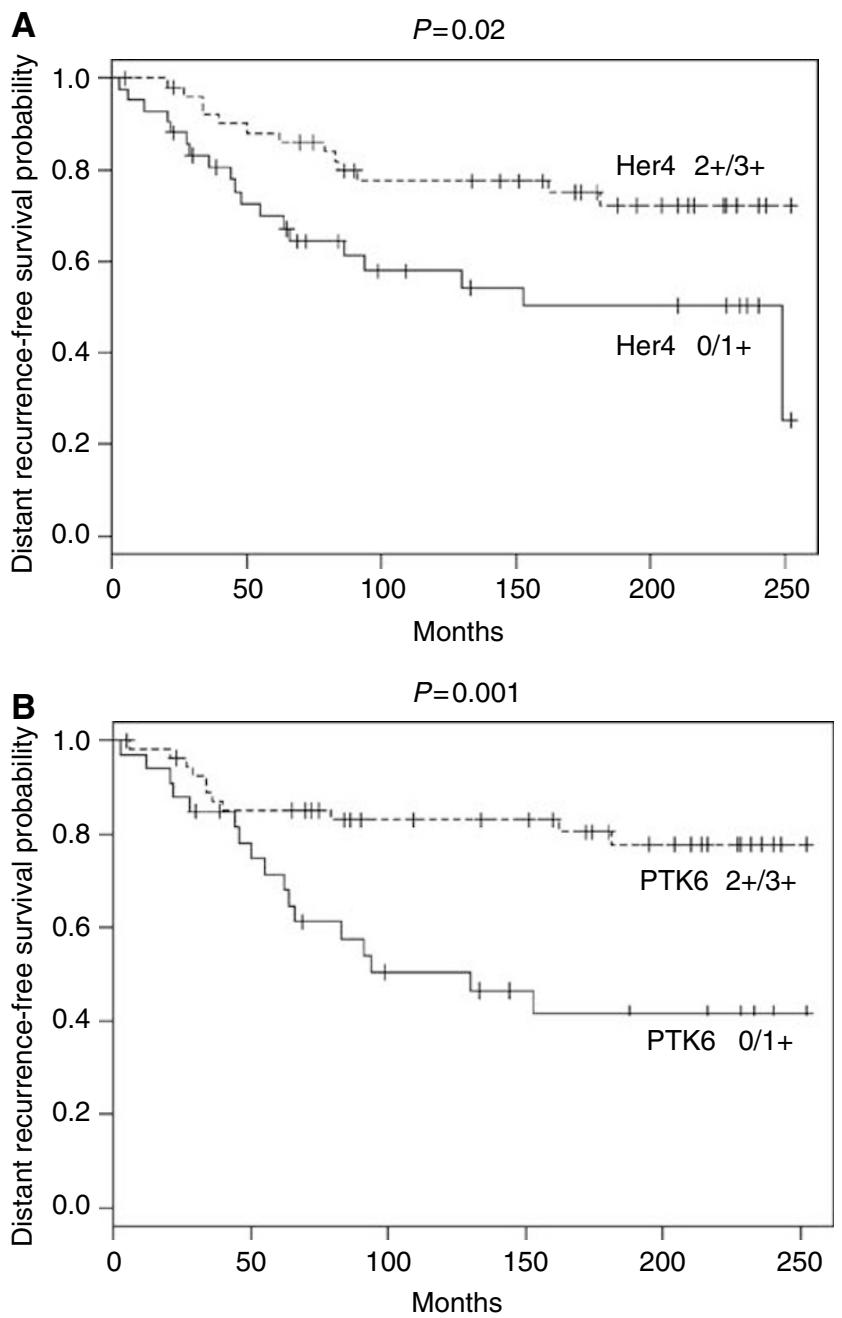

Figure 2 Kaplan-Meier curves for an event-free (distant recurrence) survival of patients of $>240$ months, with low $(0 / I+)$ vs high $(2+/ 3+)$ protein expression of HER4 $(\mathbf{A})$ and PTK6 (B). The individual groups are: HER4: low $=42$ patients, 55\% remain event-free; high $=52$ patients, $75 \%$ event-free. PTK6: low $=33$ patients, $48 \%$ event-free; high=56 patients, $80 \%$ event-free. 
Table 5 Results of the Cox multivariate regression analysis

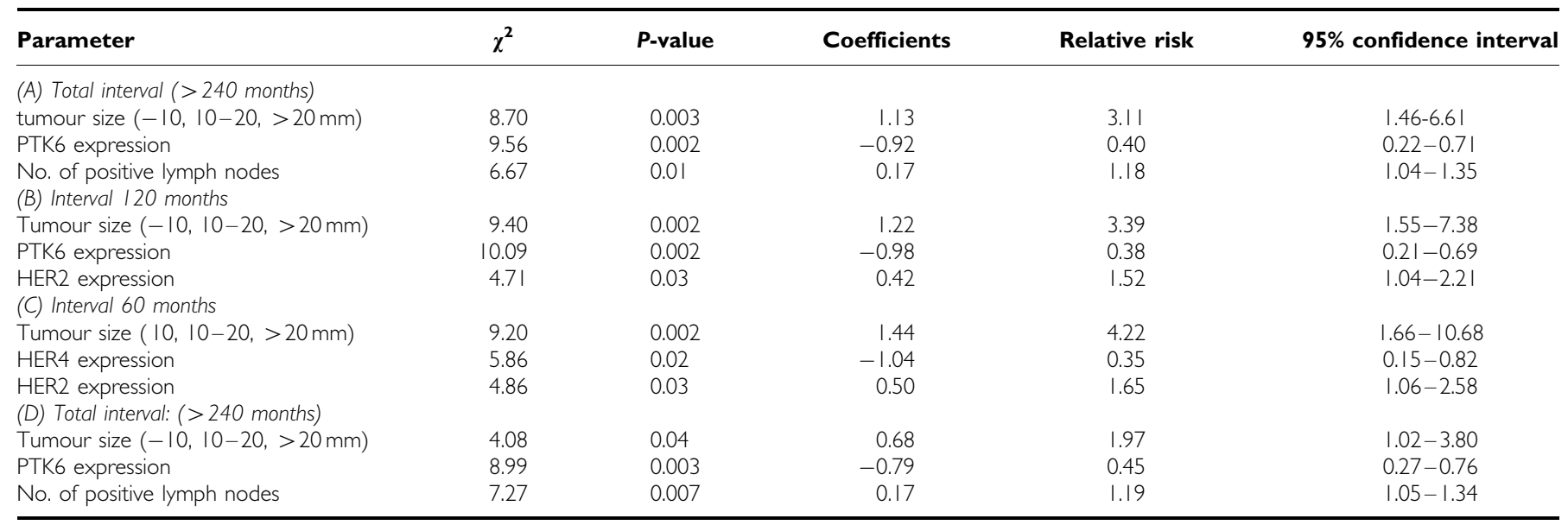

The summary of stepwise selected parameters is given for an event-free (distant recurrence) survival of $>240$ months (A), 120 months (B), and 60 months (C), and for a disease-free survival of $>240$ months (D) (positive coefficients increase, and negative coefficients reduce the risk of an event).

trends: whereas the protein expression of the HER receptors is of significant prognostic value within the first years, and PTK6 has weak prognostic meaning for this interval, the HER receptors are less important and the PTK6 is of high independent prognostic value for longer intervals (120 and 240 months). The stepwise selected parameters for a disease-free survival of patients of $>240$ months are summarised in Table 5D.

To illustrate one result of the multivariate analysis, a multivariate $\mathrm{PF}$ was calculated for each individual patient by the following linear combination of the variables, weighted by their coefficients (event-free survival 240 months) (Aubele et al, 1995):

$$
\begin{aligned}
\mathrm{PF}= & 1.13 \times \text { tumour size }+0.17 \times \text { no. positive } l y m p h \text { nodes } \\
& -0.92 \times \text { PTK } 6 .
\end{aligned}
$$

This calculation lead to a continuous variable in a range of -1.63 to 3.24. For Kaplan-Meier analysis, the patients were grouped according to their PF. The resulting curves (Figure 3) demonstrate that $91 \%$ of patients with low PF (-1.63 to 0.4$)$ stayed free of distant metastases, whereas from patients with the highest PF $(1.5-3.24)$ only $43 \%$ remain metastases-free.

\section{DISCUSSION}

In this study, we investigated the protein expression of the HER receptor family (HER1-HER4) and the cytoplasmic tyrosine kinase PTK6 in archival tissue from 193 breast carcinomas, and tested the association between markers and patient prognosis.

Studies on HER receptors in breast carcinoma so far focused mainly on HER1 and HER2, only some groups have evaluated the expression of the entire HER family (Bieche et al, 2003; Hudelist et al, 2003; Lodge et al, 2003; Witton et al, 2003; Abd El-Rehim et al, 2004; Wiseman et al, 2005; Bianchi et al, 2006). Those studies have demonstrated the importance of investigating these related proteins in the context of their ability to cooperatively modify intracellular signalling pathways (Bieche et al, 2003; Hudelist et al, 2003; Lodge et al, 2003; Witton et al, 2003; Abd El-Rehim et al, 2004; Tovey et al, 2005; Wiseman et al, 2005, Bianchi et al, 2006). We observed in our study strong overexpression $2+13+(2+/ 3+)$ of the HER receptors rarely for HER1 (5\% of tumours), most frequently for HER2 (26\%), HER3 (74\%), and for HER4 (51\% of the tumours), in general in agreement with other studies (Bieche et al, 2003; Witton et al, 2003; Abd El-Rehim et al, 2004). The frequency of combined

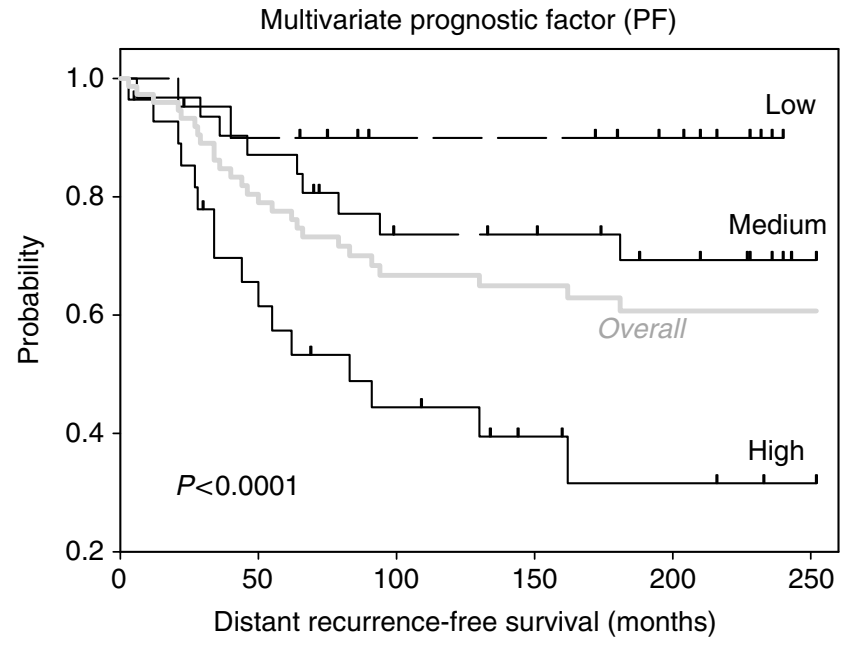

Figure 3 Kaplan-Meier curves for the event-free (distant recurrence) survival of patients of $>240$ months. Grouping of patients according to their multivariate PF resulted in three different risk groups: low PF $(-1.63$ to $\leqslant 0.4)$ : 21 patients, $91 \%$ remain event-free; medium $(0.4$ to $\leqslant 1.5): 31$ patients, 7I\% event-free; high PF (1.5-3.24): 28 patients, only $43 \%$ eventfree. In addition, the overall event-free survival of all patients is plotted in grey.

high overexpression $2+/ 3+(2+/ 3+)$ of individual HER receptors, which may point to the predominant HER heterodimerization partners in tumours, generally corresponds with other studies (Alimandi et al, 1995; Holbro, 2003; Hudelist et al, 2003; Witton et al, 2003; Abd El-Rehim et al, 2004; DiGiovanna et al, 2005; Wiseman et al, 2005). However, a high co-overexpression of HER3 - HER 4 in our study was most frequent (37\% of tumours) among the HER receptors. We also could not confirm a relationship between HER $1-3$ and the ER, as was shown by Witton et al (2003). Those contrary results may be explained by the different patient cohorts investigated and the low number of ER-positive cases in our cohort.

Overexpression of the HER1 and/or HER2 receptors by breast tumours generally predicts poor patient prognosis (Slamon 1990; Witton et al, 2003; Abd El-Rehim et al, 2004; Wiseman et al, 2005), corresponding to our findings. The prognostic significance of 
HER 3 and HER4 expression in breast carcinoma differs in several reports (Kew et al, 2000; Suo et al, 2002; Bieche et al, 2003; Witton et al, 2003; Abd El-Rehim et al, 2004; Tovey et al, 2004). As, for example, mRNA overexpression of HER3 and HER4 corresponded to a worse prognosis (Bieche et al, 2003), whereas combined HER3 - HER4 expression showed association with better outcome in another study (Abd El-Rehim et al, 2004). Although Wiseman et al (2005) did not find a relationship between HER4 expression and patient outcome, in most other studies patients with HER4 overexpression were shown to have increased survival (Suo et al, 2002; Witton et al, 2003; Abd El-Rehim et al, 2004; Tovey et al, 2004). The latter is also in good agreement with our findings here, where high HER4 expression shows a direct correlation with the event-free (distant recurrence) survival of patients. Our multivariate results further show independent prognostic values for HER2 and HER4 expression 60 (60 months), and HER2 expression 120 (120 months); however, these results are dependent on the time interval investigated. A similar time dependence in a prognostic marker has been reported by Tovey et al (2005). Investigating ER-positive tamoxifen-treated patients, the authors demonstrated a time-dependent predictive value of $\mathrm{PR}$ and HER1-3 expression and identified patients at high risk of tamoxifen resistance only in the first 3 years of treatment. This time dependency of the prognostic importance of parameters as well as investigation of different tumour cohorts may explain at least some of the contradictary results in the literature about prognostic value of the HER receptors.

Expression of PTK6 in conjunction with that of the HER receptors has not previously been analysed in breast cancer tissue. We identified a high co-overexpression of PTK6 less frequently with HER1 or HER2 (less than 18\%), and more frequent with HER4 (34\%) and with HER3 (40\% of the tumours). We further found a significant correlation between PTK6 and HER2 at the protein level, confirming our results in a recent mRNA study (Born et al, 2005). In the study presented here, strong correlations were also identified between PTK6 and HER3, and HER4, which delivers further support to the theory that PTK6 plays a functional role in the HER signalling network.

PTK6 expression and its cellular consequences in tissues appear paradoxical. In normal breast epithelium, PTK6 is low or undetectable, but the protein is overexpressed in many breast carcinomas (Petro et al, 2004; Zhang et al, 2005), suggesting, PTK6 expression is related to carcinogenesis. In contrast, high levels of PTK6 are expressed in some differentiating epithelial tissues such as normal gastrointestinal tract, skin (Llor et al, 1999; Haegebarth et al, 2004), and prostate (Derry et al, 2003), and PTK6 expression was associated with the degree of differentiation of breast tissue as indicated by ER expression (Zhao et al, 2003). The correlation of PTK6 protein expression with the histological tumour grade observed in our study may also support an association between PTK6 and cell differentiation.

The most striking result in our study is the previously undescribed prognostic relevance of the PTK6 protein expression established using multivariate survival analysis. The time dependence of HER2/HER4/PTK6 expression, relative to survival analysis, may be an important observation. We hypothesise that PTK6 could be a cytoplasmic target influencing the biological response of HER receptor signalling, particularly in the context of HER4 expression. It is well accepted that different HER receptors transduce signals through associations with a variety of cytoplasmic target proteins containing $\mathrm{SH} 2$ and/or SH3 domains (Zhang et al, 2005). PTK6 possesses both SH2 and SH3 domains (Kamalati et al, 1996; Zhang et al, 2005), which might enable it to participate in signalling processes. On the basis of our results here, there appears to be an interplay between PTK6 as an indicator and the HER receptors as prognostic markers, in particular HER4. The longterm prognostic value of PTK6, namely that it is the strongest prognostic marker at 240 months but not at 60 months may further support a role for PTK6 in promoting differentiation of tumour cells. Although HER4 expression (low/high) shows prognostic power over the first 5 years of follow-up (Figure 2), survival curves relative to PTK6 expression do not separate during the first 50 months. Longer follow-up, however, suggests a greater prognostic significance for PTK6 expression than HER4. It should be noted that, both markers are strongly correlated and both are directly correlated with favourable clinical outcome, suggesting that they represent competing drivers in multivariate analysis.

To our knowledge, this is the first study describing an independent prognostic value for PTK6 in breast carcinomas, and the association between expression of PTK6 and the HER receptors. These data suggest that PTK6 may have an important role in the signal transduction of HER expressing tumour cells as signalling modifier. Further, our results emphasise not only the need of investigating all four HERs, but also relevant intracellular signalling markers, such as CTK's, which may markedly modify the biological response to extracellular ligands. Kinomic profiling of signalling pathways may provide additional insights to the clinical relevance of key 'nodes' in these pathways. The relevance of the time dependence of the markers employed suggests these markers select different subgroups of patients with different prognosis. The combinations of proteomic markers identified here require further investigation in the context of specific treatment regimens in a predictive study large enough to probe their relevance in the context of breast cancer therapy.

\section{ACKNOWLEDGEMENTS}

We gratefully acknowledge the excellent technical assistance of Ilse DiGrazia, Uli Reich, and Elenore Samson. This project was partly supported by the European Commisson, 'TRANSBIG'Project, contract no. LSHC-CT-2004-503426, and by the Deutsche Krebshilfe, contract no. 10379. Ethical approval for this study was obtained from the Ethics Committee of the Medical Faculty of the Technical University of Munich.

\section{REFERENCES}

Abd El-Rehim DM, Pinder SE, Paish CE, Bell JA, Rampaul RS, Blamey RW, Robertson JF, Nicholson RI, Ellis IO (2004) Expression and coexpression of the members of the epidermal growth factor receptor (EGFR) family in invasive breast carcinoma. $\mathrm{Br} J$ Cancer 91: $1532-1542$

Alimandi M, Romano A, Curia MC, Muraro R, Fedi P, Aaronson SA, Di Fiore PP, Kraus MH (1995) Cooperative signaling of ErbB3 and ErbB2 in neoplastic transformation and human mammary carcinomas. Oncogene 10: $1813-1821$

Allison PD (1995) Survival Analysis Using the SAS System: A Practical Guide. Cary, NC, USA: SAS Insitute Inc

Aubele M, Auer G, Voss A, Falkmer U, Rutquist LE, Hofler H (1995) Different risk groups in node-negative breast cancer: prognostic value of cytophotometrically assessed DNA, morphometry and texture. Int $J$ Cancer 63: 7-12

Barker KT, Jackson LE, Crompton MR (1997) BRK tyrosine kinase expression in a high proportion of human breast carcinomas. Oncogene 15: $799-805$

Bianchi S, Palli D, Falchetti M, Saieva C, Masala G, Mancini B, Lupi R, Noviello C, Omerovic J, Paglierani M, Vezzosi V, Alimandi M, MarianiCostantini R, Ottini L (2006) ErbB-receptors expression and survival in breast carcinoma: a 15-year follow-up study. J Cell Physiol 206: $702-708$ 
Bieche I, Onody P, Tozlu S, Driouch K, Vidaud M, Lidereau R (2003) Prognostic value of ERBB family mRNA expression in breast carcinomas. Int J Cancer 106: $758-765$

Born M, Quintanilla-Fend L, Braselmann H, Reich U, Richter M, Hutzler P, Aubele M (2005) Simultaneous over-expression of the Her2/neu and PTK6 tyrosine kinases in archival invasive ductal breast carcinomas. J Pathol 205: $592-596$

Chen HY, Shen CH, Tsai YT, Lin FC, Huang YP, Chen RH (2004) Brk activates racl and promotes cell migration and invasion by phosphorylating paxillin. Mol Cell Biol 24: $10558-10572$

Derry JJ, Prins GS, Ray V, Tyner AL (2003) Altered localization and activity of the intracellular tyrosine kinase BRK/Sik in prostate tumor cells. Oncogene 22: $4212-4220$

DiGiovanna MP, Stern DF, Edgerton SM, Whalen SG, Moore II D, Thor AD (2005) Relationship of epidermal growth factor receptor expression to ErbB-2 signaling activity and prognosis in breast cancer patients. J Clin Oncol 23: $1152-1160$

Ellis MJ, Coop A, Singh B, Mauriac L, Llombert-Cussac A, Janicke F, Miller WR, Evans DB, Dugan M, Brady C, Quebe-Fehling E, Borgs M (2001) Letrozole is more effective neoadjuvant endocrine therapy than tamoxifen for ErbB-1- and/or ErbB-2-positive, estrogen receptor-positive primary breast cancer: evidence from a phase III randomized trial. J Clin Oncol 19: $3808-3816$

Elston CW, Ellis IO (1991) Pathological prognostic factors in breast cancer I. The value of histological grade in breast cancer: experience from a large study with long-term follow-up. Histopathology 19: 403-410

Haegebarth A, Heap D, Bie W, Derry JJ, Richard S, Tyner AL (2004) The nuclear tyrosine kinase BRK/Sik phosphorylates and inhibits the RNAbinding activities of the Sam68-like mammalian proteins SLM-1 and SLM-2. I Biol Chem 279: 54398-54404

Haegebarth A, Nunez R, Tyner AL (2005) The intracellular tyrosine kinase Brk sensitizes non-transformed cells to inducers of apoptosis. Cell Cycle 4: $1239-1246$

Holbro TBR, Maurer F, Koziczak M, Barbas III CF, Hynes NE (2003) The ErbB2/ErbB3 heterodimer functions as an oncogenic unit: ErbB2 requires ErbB3 to drive breast tumor cell proliferation. Proc Natl Acad Sci USA 100: 8933 - 8938

Hudelist G, Singer CF, Manavi M, Pischinger K, Kubista E, Czerwenka K (2003) Co-expression of ErbB-family members in human breast cancer: Her-2/neu is the preferred dimerization candidate in nodal-positive tumors. Breast Cancer Res Treat 80: $353-361$

Hynes NE, Lane HA (2005) ERBB receptors and cancer: the complexity of targeted inhibitors. Nat Rev Cancer 5: $341-354$

Jacobs TW, Gown AM, Yaziji H, Barnes MJ, Schnitt SJ (1999) Specificity of HercepTest in determining HER-2/neu status of breast cancers using the United States Food and Drug Administration-approved scoring system. J Clin Oncol 17: $1983-1987$

Kamalati T, Jolin HE, Fry MJ, Crompton MR (2000) Expression of the BRK tyrosine kinase in mammary epithelial cells enhances the coupling of EGF signalling to PI 3-kinase and Akt, via erbB3 phosphorylation. Oncogene 19: 5471 - 5476

Kamalati T, Jolin HE, Mitchell PJ, Barker KT, Jackson LE, Dean CJ, Page MJ, Gusterson BA, Crompton MR (1996) Brk, a breast tumor-derived non-receptor protein-tyrosine kinase, sensitizes mammary epithelial cells to epidermal growth factor. J Biol Chem 271: 30956 30963

Kew TY, Bell JA, Pinder SE, Denley H, Srinivasan R, Gullick WJ, Nicholson RI, Blamey RW, Ellis IO (2000) c-erbB-4 protein expression in human breast cancer. $\mathrm{Br}$ J Cancer 82: $1163-1170$
Llor X, Serfas MS, Bie W, Vasioukhin V, Polonskaia M, Derry J, Abbott CM, Tyner AL (1999) BRK/Sik expression in the gastrointestinal tract and in colon tumors. Clin Cancer Res 5: 1767-1777

Lodge AJ, Anderson JJ, Gullick WJ, Haugk B, Leonard RC, Angus B (2003) Type 1 growth factor receptor expression in node positive breast cancer: adverse prognostic significance of c-erbB-4. J Clin Pathol 56: $300-304$

Menard S, Pupa SM, Campiglio M, Tagliabue E (2003) Biologic and therapeutic role of HER2 in cancer. Oncogene 22: 6570-6578

Mendelsohn J, Baselga J (2000) The EGF receptor family as targets for cancer therapy. Oncogene 19: 6550-6565

Meric F, Lee WP, Sahin A, Zhang H, Kung HJ, Hung MC (2002) Expression profile of tyrosine kinases in breast cancer. Clin Cancer Res 8: $361-367$

Mitchell PJ, Barker KT, Martindale JE, Kamalati T, Lowe PN, Page MJ, Gusterson BA, Crompton MR (1994) Cloning and characterisation of cDNAs encoding a novel non-receptor tyrosine kinase, brk, expressed in human breast tumours. Oncogene 9: 2383-2390

Olayioye MA, Neve RM, Lane HA, Hynes NE (2000) The ErbB signaling network: receptor heterodimerization in development and cancer. $E M B O$ J 19: $3159-3167$

Petro BJ, Tan RC, Tyner AL, Lingen MW, Watanabe K (2004) Differential expression of the non-receptor tyrosine kinase BRK in oral squamous cell carcinoma and normal oral epithelium. Oral Oncol 40: 1040-1047

Quintanilla-Martinez L, Davies-Hill T, Fend F, Calzada-Wack J, Sorbara L, Campo E, Jaffe ES, Raffeld M (2003) Sequestration of p27Kip1 protein by cyclin D1 in typical and blastic variants of mantle cell lymphoma (MCL): implications for pathogenesis. Blood 101: 3181-3187

Richter J, Wagner U, Kononen J, Fijan A, Bruderer J, Schmid U, Ackermann D, Maurer R, Alund G, Knonagel H, Rist M, Wilber K, Anabitarte M, Hering F, Hardmeier T, Schonenberger A, Flury R, Jager P, Fehr JL, Schraml P, Moch H, Mihatsch MJ, Gasser T, Kallioniemi OP, Sauter G (2000) High-throughput tissue microarray analysis of cyclin E gene amplification and overexpression in urinary bladder cancer. Am J Pathol 157: $787-794$

Slamon DJ (1990) Studies of the HER-2/neu proto-oncogene in human breast cancer. Cancer Invest 8: 253

Suo Z, Risberg B, Kalsson MG, Willman K, Tierens A, Skovlund E, Nesland JM (2002) EGFR family expression in breast carcinomas c-erbB- 2 and cerbB-4 receptors have different effects on survival. J Pathol 196: $17-25$

Tovey S, Dunne B, Witton CJ, Forsyth A, Cooke TG, Bartlett JM (2005) Can molecular markers predict when to implement treatment with aromatase inhibitors in invasive breast cancer? Clin Cancer Res 11: 4835-4842

Tovey SM, Witton CJ, Bartlett JM, Stanton PD, Reeves JR, Cooke TG (2004) Outcome and human epidermal growth factor receptor (HER) 1-4 status in invasive breast carcinomas with proliferation indices evaluated by bromodeoxyuridine labelling. Breast Cancer Res 6: R246-251

Wiseman SM, Makretsov N, Nielsen TO, Gilks B, Yorida E, Cheang M, Turbin D, Gelmon K, Huntsman DG (2005) Coexpression of the type 1 growth factor receptor family members HER-1, HER-2, and HER-3 has a synergistic negative prognostic effect on breast carcinoma survival. Cancer 103: 1770 - 1777

Witton CJ, Reeves JR, Going JJ, Cooke TG, Bartlett JM (2003) Expression of the HER1-4 family of receptor tyrosine kinases in breast cancer. J Pathol 200: $290-297$

Zhang P, Ostrander JH, Faivre EJ, Olsen A, Fitzsimmons D, Lange CA (2005) Regulated association of protein kinase B/Akt with breast tumor kinase. J Biol Chem 280: $1982-1991$

Zhao C, Yasui K, Lee CJ, Kurioka H, Hosokawa Y, Oka T, Inazawa J (2003) Elevated expression levels of NCOA3, TOP1, and TFAP2C in breast tumors as predictors of poor prognosis. Cancer 98: 18-23 